\title{
Intralesional Interferon Alfa-2b Regimen
}

National Cancer Institute

\section{Source}

National Cancer Institute. Intralesional Interferon Alfa-2b Regimen. NCI Thesaurus. Code C160062.

A chemotherapy regimen consisting of intralesional interferon alfa- $2 b$ that may be used in the treatment of cutaneous melanoma. 